\title{
EARLY EPISODES OF HYPOCARBIA AND EARLY-ONSET SEPSIS ARE RISK FACTORS FOR CYSTIC PERIVENTRICULAR LEUKOMALACIA IN THE PRETERM INFANT
}

\author{
B. Resch, K. Neubauer, N. Hofer, E. Resch, U. Maurer, J. Haas, W. Müller \\ Medical University of Graz, Graz, Austria
}

Background: The pathogenesis of cystic periventricular leukomalacia (cPVL) is based on an either hypoxicischemic and/or inflammatory processes with different risk factors having been postulated to be associated with its development. We aimed to evaluate risk factors for $\mathrm{CPVL}$ focussing on the influence of hypocarbia.

Patients and methods: Single centre retrospective cohort study at a tertiary care university NICU between 1999 and 2008. All preterm infants $\leq 35$ weeks gestational age with diagnosis of cPVL by serial cranial ultrasound were compared with two controls matched for gestational age ( \pm 1 week), birth weight $( \pm 200$ grams), sex, and year of birth.

Results: 47 preterm infants were diagnosed as having cPVL. Univariate analysis of risk factors revealed lower 5 and 10 minutes Apgar scores, and higher rates of neonatal seizures, early-onset sepsis, neonatal steroids, respiratory distress syndrome with surfactant replacement therapy, and episodes of hypocarbia significantly being associated with cPVL. In-vitro fertilisation, caesarean section, and preeclampsia were negatively correlated with cPVL. Following multivariate analysis using a logistic regression model and including all parameters with a level of significance below 0.1 early-onset sepsis and hypocarbia remained the only significantly associated risk factors $(\mathrm{p}=0.022$ and 0.024 , respectively). Lowest $\mathrm{PaCO} 2$ values did not differ between cPVL cases and controls as did not the duration of hypocarbia, but the onset of hypocarbia was significantly later in cPVL cases.

Conclusion: Early episodes of hypocarbia and sepsis are risk factors for the development of cPVL in the preterm infant. 